\title{
ELEMENTOS DE CONTEXTO SOBRE FILOSOFÍA Y NIÑEZ
}

\section{David Rojas Lizama}

Asociación Filosofía y Sociedad, Chile. Fono:+569 6140 7267. Correo electrónico: davidrojaslizama@gmail.com

\section{Estimado Editor:}

La idea de integrar filosofía en educación escolar y parvularia tiene sus inicios con el movimiento de "filosofía para niños" — posteriormente "con niños" - que comenzó con Matthew Lipman, y tiene actualmente una expresión latinoamericana en la obra de Walter Kohan, de quienes algunas ideas se presentan sucintamente en esta carta.

Matthew Lipman notó que los universitarios de primer año no tenían una buena base de habilidades de razonamiento, lo cual lo hizo considerar que el pensamiento no debía ser algo que se dejara sólo para edades tardías. De esta manera, comienza a escribir novelas para niños que ayudan a desarrollar habilidades de razonamiento desde los 3 años ( $c f$. Echeverría, 2004).

Estas habilidades no se aprenden mediante ejercicios formales — como en el caso de las ciencias formales - sino, al contrario, a través de contenidos que se van develando en el transcurso de las lecciones. En este sentido, sus obras "recapitulan las principales ideas y conceptos filosóficos que han surgido a lo largo de la historia del ser humano" (Echeverría 2004: 14).

Una de sus ideas metodológicas fundamentales es que cada niño se vincule con otros para formar comunidades de indagación.

Por indagación entendemos, por su puesto, constancia en la exploración auto correctiva de temas que se perciben al mismo tiempo como algo problemático e importante. De ningún modo queremos decir que la indagación ponga mayor interés en el descubrimiento, o en actividades gobernadas por reglas que en actividades improvisadas. Los que crean obras de artes practican esa indagación tanto como los que escriben nuevos tratados (Lipman et al. 1992: 40; cita adecuada). 
Junto a las comunidades de indagación, la filosofía a esta edad colabora a no ver el currículo como algo fragmentado. Al contrario, "la filosofía forma, por decirlo así, un ángulo recto con las otras disciplinas de tal manera que, como la trama y la urdimbre, se entrelazan hasta producir un tejido sin costuras" (Lipman et al. 1992: 45).

No obstante, uno de los problemas de Lipman es que presupone una idea de niño basada en el desarrollo de las habilidades de razonamiento: su educación es preescolar en el sentido en que los niños deben tender hacia su escolarización. Es por esto que, cuando menciona los objetivos de su obra para la etapa "preescolar-7 años", sostiene que en ella "se insiste en la adquisición del lenguaje" (Lipman et al. 1992: 126) — tomando, entonces, al niño como a un in-fans o falto de lenguaje.

Walter Kohan describe de forma crítica las implicancias de las distintas ideas de infancia que consideran al niño y la niña como sujetos incompletos. Entre ellas, destacan la infancia como inferioridad, la infancia como un otro despreciado, la infancia como material de la política (o idea de que los niños deben formarse como buenos ciudadanos), la infancia escolarizada como construcción política (o la idea de infancia inventada en la modernidad) y la infancia como punto de llegada (base de los intentos de infantilizar la escuela, dirección opuesta a escolarizar la infancia). Todas estas ideas de infancia son determinadas por relaciones de dominación que fundamentan una visión asimétrica entre una "infancia" y un "mundo adulto" (cf. Kohan, 2004: parte 1).

Valga mencionar que distintas partes de las nociones mencionadas de niño, componen la visión de una infancia receptora de garantías abstractas: una idea abstracta de niño (en masculino y singular) que está presupuesta en la Convención Internacional de los Derechos del Niño. En este sentido, esta idea abstracta constituye:

Un modelo de niño que responde a los estándares culturales, económicos, sociales y políticos dominantes de una sociedad, que se autodenomina madura, responsable, consciente y que pretende legislar para todas las otras: es un modelo producido por adultos (Kohan, 2009: 27)

En oposición, Kohan propone una idea de infancia que se distingue por su valor en sí misma. En este marco, se concibe al sujeto de la infancia como un sujeto cuyas 
experiencias son más ricas en intensidad que las de los adultos, aunque estos hayan tenido una amplia gama de otras experiencias durante un tiempo cronológico más largo.

Para representarlo, Kohan toma prestado de los griegos tres formas de pensar el tiempo:

Los antiguos griegos tenían varias palabras para decir y pensar el tiempo. Una de ellas es chrónos, que designa la continuidad de un tiempo sucesivo (...) Otra palabra para designar el tiempo entre los antiguos griegos es kairós, que significa "medida", "proporción”, y, en relación con el tiempo, "momento crítico", "temporada", “oportunidad”. Finalmente, (...) aión designa la intensidad del tiempo de la vida humana, un destino, una duración, una temporalidad no numerable ni sucesiva, sino intensiva. (...) Lo que sugiere este pensamiento es que, al menos en un sentido de la temporalidad [el sentido intensivo o aiónico], los niños están más despiertos y atentos, y son por lo tanto más poderosos que los adultos. (Kohan, 2009: 18-19, itálicas añadidas)

Estas tres maneras de pensar el tiempo le otorgan a la infancia una primacía concreta sobre otras etapas de la vida, un poder y una política específica. En otras palabras,

Si acordamos que un niño es más poderoso en términos de aión que de chrónos, entonces surge de allí una experiencia de tiempo no cronológica, aiónica, simultáneamente con un concepto no cronológico de la infancia: si esto es así, entonces la infancia puede ser no solamente un periodo de la vida, sino una forma específica de experiencia en la vida.

(Kohan, 2008; citado en Hecker y Rebagliati, 2009: 176; itálicas añadidas).

En síntesis, esta forma de pensar la niñez nos llama la atención sobre una forma específica de experiencia, como un espacio de poder, diverso, alegre y valioso en sí mismo por su intensidad vital, más que como una etapa determinada por un rango de edad que sirve como proceso de preparación para la etapa adulta.

Por último, esta manera de repensar la niñez constituye un llamado a comprender políticamente el espacio de la niñez en concreto, y combatir, por tanto, las ideas abstractas de niño presupuestas en algunas políticas de infancia y sus marcos normativos superiores.

\section{Referencias bibliográficas}

Echeverría, E. (2006) Filosofía para niños, Ed. SM 
Hecker, A. y Rebagliati, M. S. (2009) "Tiempos y cuerpos en el filosofar de la infancia”, Childhood \& Philosophy, Río de Janeiro, v. 5, no. 9

Kohan W. (2009) Infancia y filosofía, Ed. Progreso

Kohan, W. (2004) Infancia, entre filosofía y educación, Ed. Laertes

Lipman, M., A. M. Sharp y F. S. Oscayán (1992), La filosofía en el aula, Ed. De la Torre 